\title{
PENERAPAN METODE COKRIGING UNTUK MENGESTIMASI JUMLAH ZAT PADAT TERLARUT PADA AIR DI PERMUKIMAN KOTA PONTIANAK
}

\author{
Naomi Nessyana Debataraja \\ Dadan Kusnandar \\ Nurfitri Imro'ah \\ Marwalida Rachmadiar \\ Program Studi Statistika, Universitas Tanjungpura, Pontianak \\ e-mail: naominessyana@math.untan.ac.id
}

\begin{abstract}
The aim of this study is to apply cokriging method in estimating solid substance from water sample in the city of Pontianak. Cokriging is a method to estimate a variable using cross correlation among severa variables. The sample is water from 41 location in housing areas in Pontianak. Measurement of dissolved solid substance level and colors in a laboratory. Based on the result, a theoretical semivariogram model is developed of dissolved solid substance level and spherical model for color. Cross semivariogram model between content of dissolved solid substance and coloris spherical model. The study also showed estimation value of dissolved solid substance for ten new location in housing area of Pontianak city which are not studied previously. The estimation showed that the largest dissolved solid sbubstance is $155,4 \mathrm{mg} / \mathrm{L}$ and the smallest is $11,7 \mathrm{mg} / \mathrm{L}$. A visualization of the locations are shown in a map by Geographical Information System.
\end{abstract}

Keywords: spatial, semivariogram, kriging, Geographic Information Systems

\begin{abstract}
ABSTRAK
Metode cokriging adalah metode yang digunakan untuk mengestimasi suatu variabel dengan memanfaatkan korelasi silang antara beberapa variabel. Penelitan ini bertujuan untuk mengaplikasikan metode cokriging dalam mengestimasi kandungan jumlah zat padat terlarut dari kandungan warna air di kawasan permukiman Kota Pontianak. Data yang digunakan adalah sampel air dari 41 lokasi di kawasan permukiman Kota Pontianak. Setiap sampel air dilakukan pengukuran nilai jumlah zat padat terlarut dan warna di laboratorium. Dari hasil analisis diperoleh model semivariogram teoritis untuk jumlah zat padat terlarut yang digunakan adalah model eksponensial, sedangkan untuk warna adalah model spherical. Model cross semivariogram antara jumlah zat padat terlarut dan warna yang digunakan adalah model spherical. Selanjutnya diperoleh nilai estimasi dari jumlah zat padat terlarut untuk sepuluh titik lokasi baru di kawasan permukiman Kota Pontianak yang belum tersampel. Hasil estimasi menunjukkan nilai jumlah zat padat terlarut terbesar sebesar 155,4 mg/L dan terkecil di parit sebesar 11,7 mg/L. Titik-titik lokasi divisualisasikan dalam bentuk peta melalui Sistem Informasi Geografis.
\end{abstract}

Kata kunci: spasial, semivariogram, kriging, Sistem Informasi Geografis 
Manfaat air bagi keperluan higiene sanitasi untuk kehidupan manusia sangat banyak seperti mandi, sikat gigi, cuci dan keperluan sehari-hari. Laju pertumbuhan penduduk yang bertambah dari tahun ke tahun berbanding lurus dengan meningkatnya kepadatan penduduk di kawasan permukiman. Akibatnya, aktivitas manusia merupakan salah satu faktor penyebab penurunan kualitas air di daerah tersebut. Berdasarkan Peraturan Menteri Kesehatan Republik Indonesia Nomor 32 Tahun 2017, standar baku mutu kesehatan lingkungan untuk air bagi keperluan higiene sanitasi meliputi indikator fisik, kimia dan biologi. Dalam indikator fisik, variabel yang termasuk di antaranya adalah variabel jumlah zat padat terlarut (Total Dissolved Solid) yang biasa disingkat dengan TDS dan variabel warna. TDS adalah indikator yang menunjukkan kandungan padatan terlarut dalam air yang termasuk di dalamnya senyawa-senyawa organik dan anorganik, mineral dan garam-garamnya. Semakin tinggi kadar TDS dalam air, maka semakin rendah pula kualitas air tersebut atau dapat dikatakan pencemaran air semakin tinggi. Kadar TDS dalam air untuk keperluan higiene sanitasi maksimal $1000 \mathrm{mg} / \mathrm{L}$. Indikator fisik yang lain adalah warna air. Air dapat dikategorikan baik jika air tidak bewarna atau bening. Kandungan zat warna air tidak boleh melebihi 50 True Color Unit (TCU).

Kadar TDS diperoleh dengan tahapan mengambil sampel kandungan TDS di suatu lokasi dan dilakukan pengujian sampel di laboratorium. Semakin banyak sampel yang diuji, semakin banyak juga dana yang dibutuhkan. Karena keterbatasan dalam penelitian, lokasi yang diambil sampel airnya juga terbatas. Kadar TDS di lokasi yang tidak dijadikan sampel dapat diestimasi dengan menggunakan kadar TDS di lokasi sekitarnya. Salah satu metode yang dapat digunakan adalah cokriging. Cokriging merupakan metode untuk menaksir dengan meminimalkan varians kesalahan estimasi, yang diperoleh dari korelasi silang antara beberapa variabel (Isaaks \& Srivastava, 1989). Cokriging menggunakan variabel tambahan yang biasa disebut juga sebagai kovariat. Variabel tambahan tersebut digunakan untuk mengestimasi variabel utama pada lokasi yang tidak disampel. Estimasi cokriging merupakan kombinasi linier dari data variabel utama dan variabel tambahan. Metode cokriging menggunakan model variogram yang terbaik dalam membantu proses estimasi. Penelitian ini dapat membantu memberi gambaran kepada masyarakat tentang kualitas air di kawasan permukiman Kota Pontianak yang tercermin dari kadar TDS.

\section{METODE}

Data yang digunakan pada penelitian ini adalah data penelitian mengenai kandungan TDS dan warna dalam air di kawasan permukiman Kota Pontianak. Pengambilan lokasi sampel dilakukan dengan metode stratified random sampling di Kota Pontianak. Populasi dikelompokan menjadi subpopulasi yang dibentuk berdasarkan kriteria daerah yang dialiri oleh anak sungai yang sama.

Dari setiap subpopulasi diambil titik-titik lokasi yang menjadi sampel (Debataraja, Kusnandar \& Nusantara, 2018). Penelitian ini menggunakan data titik lokasi yang berupa koordinat garis bujur dan lintang yang dikonversi menjadi easting dan northing $(\mathrm{x}, \mathrm{y})$. Variabel utama adalah variabel TDS (satuannya $\mathrm{mg} / \mathrm{L}$ ), sedangkan variabel tambahan yang digunakan untuk mengestimasi variabel utama adalah warna (satuannya TCU). Titik lokasi sebanyak 41 sampel disajikan pada Gambar 1.

Kriging adalah teknik interpolasi linear yang menggunakan autokorelasi spasial antar pengamatan untuk mengestimasi variabel di lokasi yang tidak diambil sampelnya dengan varians minimum dan tidak bias. Kriging digunakan untuk menginterpolasi suatu nilai yang akan ditaksir berdasarkan nilai-nilai yang diketahui. Ketepatan taksiran Kriging sangat tergantung pada model semivariogram untuk menentukan bobot kriging. 


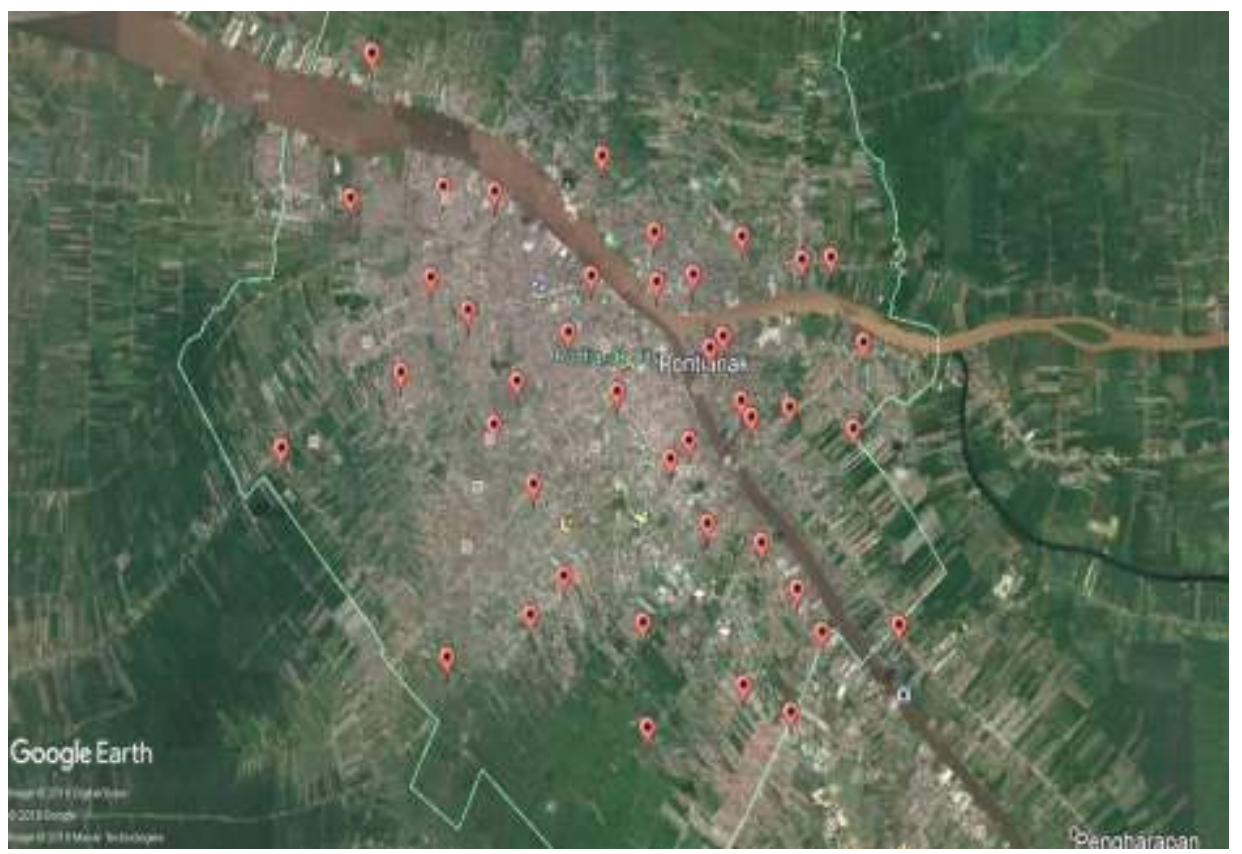

Gambar 1. Peta titik lokasi

Menurut Cressie (2015) dan Wackernagel (1995) nilai taksiran untuk data yang tidak diketahui dapat ditaksir menggunakan persamaan berikut:

$$
\hat{Z}\left(p_{0}\right)=\sum_{k=1}^{n} w_{k} Z\left(p_{k}\right)
$$

dengan $\hat{Z}\left(p_{0}\right)$ adalah nilai taksiran pengamatan pada lokasi $p_{0}, Z\left(p_{k}\right)$ adalah nilai pengamatan pada lokasi $p_{k}$, pembobot pada lokasi k didefinisikan sebagai $w_{k}$ dan banyaknya sampel yang digunakan untuk estimasi didefinisikan dengan $n$. Variogram merupakan grafik variansi terhadap jarak (lag distance). Taksiran variogram eksperimental pada jarak $h$ dapat dituliskan

$$
2 \gamma(h)=\frac{1}{N(h)} \sum_{k=1}^{N(h)}\left[z\left(s_{k}+h\right)-z\left(s_{k}\right)\right]^{2}
$$

dimana $2 \gamma(h)$ adalah variogram dengan jarak $h ; N(h)$ adalah banyaknya pasangan data untuk jarak $h$; $s_{k}$ adalah lokasi sampel ke $k$; $z\left(s_{k}\right)$ adalah nilai observasi pada lokasi $s_{k}$. Semivariogram biasanya dinotasikan dengan simbol $\gamma(h)$, yang digunakan untuk menentukan jarak dimana nilai-nilai data pengamatan menjadi tidak saling tergantung atau tidak ada korelasinya. Dalam model semivariogram terdapat tiga parameter yang perlu diperhatikan, yaitu nugget effect $\left(C_{0}\right)$, sill $\left(C_{0}+C_{1}\right)$, dan range $(a)$, yang disajikan pada Gambar 2. 


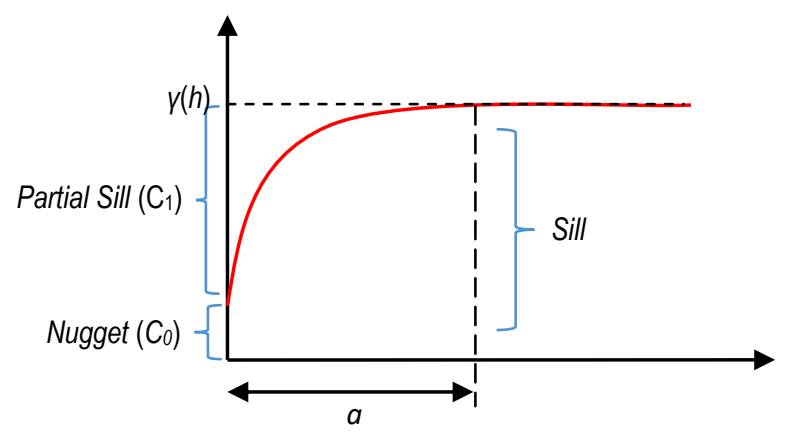

Sumber: Cressie(2015)

Gambar 2. Model semivariogram

Adapun penjelasan parameter yang terkandung dalam semivariogram terdiri dari (Armstrong, 1998):

- $\quad$ Sill

Sill adalah keadaan dimana nilai semivariogram relatif mencapai nilai yang stabil. Nilai sill diperoleh dari nilai variansi data.

- Range

Range merupakan jarak pada keadaan semivariogram mencapai sill.

- Nugget Effect

Nilai semivariogram bernilai 0 saat $\mathrm{h}=0$. Akan tetapi, jika nilai semivariogram pada $\mathrm{h}=0$ tidak bernilai 0 , maka dapat dikatakan semivariogram mempunyai nugget effect.

Penentuan model terbaik dilakukan dengan membandingkan Mean of Squared Error (MSE) dari masing-masing model semivariogram dengan rumus sebagai berikut.

$$
M S E=\frac{1}{n} \sum_{i=1}^{n}\left(\gamma\left(h_{i}\right)-\gamma\left(h_{i}\right)\right)^{2}
$$

Cokriging adalah perluasan dari kriging yang menggunakan lebih dari satu variabel. Menurut Isaaks \& Srivastava (1989), estimasi cokriging merupakan kombinasi linier dari data variabel primer dan variabel sekunder yang dinyatakan sebagai berikut.

$$
\hat{p}_{0}=\sum_{k=1}^{n} a_{k} p_{k}+\sum_{l=1}^{m} b_{l} q_{l}
$$

di mana $\hat{p}_{0}$ adalah estimasi dari $p$ pada lokasi $0 ; p_{1}, p_{2}, \ldots, p_{n}$ adalah data variabel utama pada $n$ lokasi terdekat; $q_{1}, q_{2}, \ldots, q_{m}$ adalah data variabel sekunder pada $m$ lokasi terdekat; $a_{1}, a_{2}, \ldots, a_{n}$ dan $b_{1}, b_{2}, \ldots, b_{m}$ adalah pembobot cokriging yang harus ditentukan. Pada cokriging menggunakan dua sampel acak, sehingga tidak cukup hanya menggunakan variogram yang hanya mengukur independensi spasial untuk satu variabel. Cross semivariogram dapat dituliskan sebagai berikut.

$$
\gamma_{U V}(\mathrm{~h})=\frac{1}{2} E\left[Z_{p}(\mathrm{x}+\mathrm{h})-Z_{p}(\mathrm{x})\right]\left[Z_{q}(\mathrm{x}+\mathrm{h})-Z_{q}(\mathrm{x})\right]
$$

Cross semivariogram sampel dapat dinyatakan juga sebagai berikut. 


$$
\hat{\gamma}_{U V}(\mathrm{~h})=\frac{1}{2 N(\mathrm{~h})} \sum_{(k, l) \mid \mathrm{h}_{k l}=\mathrm{h}}\left(p_{k}-p_{l}\right)\left(q_{k}-q_{l}\right)
$$

\section{HASIL DAN PEMBAHASAN}

Hasil perhitungan untuk statistik deskriptif pada variabel TDS dan warna diperoleh nilai minimal dari data TDS adalah $17,2 \mathrm{mg} / \mathrm{L}$ dan nilai maksimalnya adalah $156,3 \mathrm{mg} / \mathrm{L}$ dengan nilai ratarata $74,83 \mathrm{mg} / \mathrm{L}$. Hal ini menunjukkan TDS pada sampel air yang diambil tergolong normal.

Sedangkan nilai minimal dari variabel warna adalah 22 TCU dan nilai maksimalnya adalah 990 TCU dengan nilai rata-rata 358,51 TCU. Hasil perhitungan nilai korelasi antara TDS dan warna sebesar $-0,82$ yang hubungan antara kedua variabel kuat namun nilainya berbanding terbalik. Perhitungan semivariogram eksperimental menghasilkan jumlah pasangan data pada masing-masing kelas dan jarak dari setiap pasangan data beserta nilai semivariogramnya. Jumlah total pasangan data adalah jumlah kombinasi data TDS tersampel yaitu $C(41,2)=820$. Setelah nilai semivariogram eksperimental diperoleh, kemudian dihitung nilai semivariogram teoritis yaitu model spherical, eksponential dan gaussian. Dengan bantuan software $R$ diperoleh nilai sill dan range dari TDS. Kemudian nilai sill dan range yang didapat, digunakan dalam persamaan dari masing-masing semivariogram teoritis. Nilai semivariogram eksperimental dan teoritis dari variabel TDS disajikan pada Tabel 1.

Selanjutnya dilakukan analisis lanjutan dengan cara mengurangi nilai semivariogram eksperimental dengan teoritis yang diperoleh. Hal ini bertujuan untuk melihat model semivariogram teoritis yang terbaik yang memiliki nilai mendekati hasil semivariogram eksperimentalnya. Dari ketiga model semivariogram tersebut, nilai MSE terkecil adalah nilai semivariogram teoritis dengan model eksponensial .

Tabel 1. Nilai Semivariogram Eksperimental dan Teoritis dari Variabel TDS

\begin{tabular}{rrrrrr}
\hline $\begin{array}{c}\text { Banyaknya } \\
\text { Pasangan }\end{array}$ & \multicolumn{1}{c}{ Jarak } & $\begin{array}{c}\text { Semivariogram } \\
\text { eksperimental }\end{array}$ & Spherical & Eksponensial & Gaussian \\
\hline 87 & $1.214,6010$ & 692,45 & 900,69 & 728,60 & 892,92 \\
227 & $2.552,4620$ & $1.048,29$ & 900,69 & 991,29 & 892,93 \\
237 & $4.145,9130$ & $1.336,72$ & 900,69 & $1.079,13$ & 892,93 \\
181 & $5.781,6890$ & $2.008,72$ & 900,69 & $1.100,89$ & 892,93 \\
68 & $7.399,2370$ & $2.554,44$ & 900,69 & $1.106,00$ & 892,93 \\
18 & $8.998,3400$ & $1.880,27$ & 900,69 & $1.107,22$ & 892,93 \\
2 & $10.414,0170$ & 509,65 & 900,69 & $1.107,50$ & 892,93 \\
\hline \multicolumn{7}{c}{ MSE } & & $761.488,79$ & $564.009,07$ & $1.063 .434,72$ \\
\hline
\end{tabular}

Semivariogram teoritis model eksponensial memiliki nilai sill 1.107,61 dan range 1.132,62 yang digunakan dalam proses estimasi TDS. Dengan cara analisis yang sama pada variabel TDS, dilakukan perhitungan untuk variabel warna. Nilai semivariogram eksperimental dan teoritis dari variabel warna disajikan pada Tabel 2. 
Tabel 2. Nilai Semivariogram Teoritis dan Eksperimental dari Variabel Warna

\begin{tabular}{|c|c|c|c|c|c|}
\hline $\begin{array}{c}\text { Jumlah } \\
\text { Pasangan }\end{array}$ & Jarak & $\begin{array}{l}\text { Semivariogram } \\
\text { eksperimental }\end{array}$ & Spherical & Eksponensial & Gaussian \\
\hline 87 & $1.214,6010$ & $53.436,49$ & 50106,47 & 51539,60 & 50546,72 \\
\hline 227 & $2.552,4620$ & $86.831,00$ & 93791,38 & 90625,15 & 87807,03 \\
\hline 237 & $4.145,9130$ & $120.038,77$ & 113048,70 & 120990,87 & 90193,72 \\
\hline 181 & $5.781,6890$ & $139.740,23$ & 113048,70 & 140412,26 & 90199,98 \\
\hline 68 & $7.399,2370$ & $130.909,15$ & 113048,70 & 152327,04 & 90199,98 \\
\hline 18 & $8.998,3400$ & $143.971,72$ & 113048,70 & 159674,10 & 90199,98 \\
\hline 2 & $10.414,0170$ & $9.940,50$ & 113048,70 & 163845,70 & 90199,98 \\
\hline \multicolumn{2}{|c|}{ MSE } & & 1818194970,09 & 3487350586,04 & 2049212684,87 \\
\hline
\end{tabular}

Dari ketiga model semivariogram tersebut, nilai MSE yang paling kecil adalah nilai semivariogram teoritis dengan model spherical. Semivariogram teoritis model spherical memiliki nilai sill $113.048,70$ dan range $3.983,11$ yang digunakan dalam proses estimasi TDS. Perhitungan cross semivariogram eksperimental menghasilkan jumlah pasangan data pada masing-masing kelas dan jarak dari setiap pasangan data beserta nilai cross semivariogramnya. Jumlah total pasangan data adalah jumlah permutasi data TDS dan warna tersampel yaitu $P(41,2)=1640$. Cross Semivariogram teoritis yang adalah model spherical, eksponensial dan gaussian. Nilai cross semivariogram eksperimental dan teoritis dari variabel TDS disajikan pada Tabel 3.

Dari Tabel 3, nilai MSE yang paling kecil adalah nilai cross semivariogram teoritis dengan model spherical dengan nilai sill 10.076,32 dan range 4.167,50 yang digunakan dalam proses estimasi TDS. Dari perhitungan nilai sill dan range untuk model semivariogram pada variabel TDS dan warna, serta model cross semivariogram pada TDS dan warna digunakan untuk mengestimasi TDS di sepuluh titik lokasi baru yang telah ditentukan. Titik lokasi baru yang diestimasi adalah titik lokasi di kawasan permukiman dimana pada umumnya, air digunakan untuk keperluan higiene sanitasi.

Tabel 3. Nilai Cross Semivariogram Eksperimental danTeoritis

\begin{tabular}{ccrrrr}
\hline $\begin{array}{c}\text { Banyaknya } \\
\text { Pasangan }\end{array}$ & Jarak & $\begin{array}{c}\text { Semivariogram } \\
\text { Eksperimental }\end{array}$ & \multicolumn{1}{c}{ Spherical } & Eksponensial & \multicolumn{1}{c}{ Gaussian } \\
\hline 174 & $1.214,6010$ & $4.362,41$ & $4.280,33$ & $2.547,47$ & 820,55 \\
454 & $2.552,4620$ & $7.390,08$ & $10.076,32$ & $4.614,84$ & $3.151,79$ \\
474 & $4.145,9130$ & $10.670,44$ & $10.076,32$ & $6.350,20$ & $6.330,95$ \\
362 & $5.781,6890$ & $14.085,02$ & $10.076,32$ & $7.559,84$ & $8.605,96$ \\
136 & $7.399,2370$ & $15.896,99$ & $10.076,32$ & $8.369,34$ & $9.645,50$ \\
36 & $8.998,3400$ & $13.793,99$ & $10.076,32$ & $8.913,30$ & $9.981,12$ \\
4 & $10.414,0170$ & $2.248,95$ & $10.076,32$ & $9.248,27$ & $10.056,76$ \\
\hline \multicolumn{7}{c}{ MSE } & & $18.944 .889,59$ & $28.816 .493,68$ & $27.705 .729,70$ \\
\hline
\end{tabular}

Variabel utama yaitu TDS menggunakan model semivariogram teoritis exponential dengan nilai sill $1.107,61$ dan range 1.132,62. Sedangkan variabel warna menggunakan model semivariogram teoritis spherical dengan nilai sill 113.048,70 dan range 3.983,11. Cross semivariogram antara TDS dan 
warna menggunakan model cross semivariogram teoritis spherical dengan nilai sill 10.076,32 dan range 4.167,50. Hasil estimasi TDS untuk sepuluh lokasi baru disajikan pada Gambar 3.

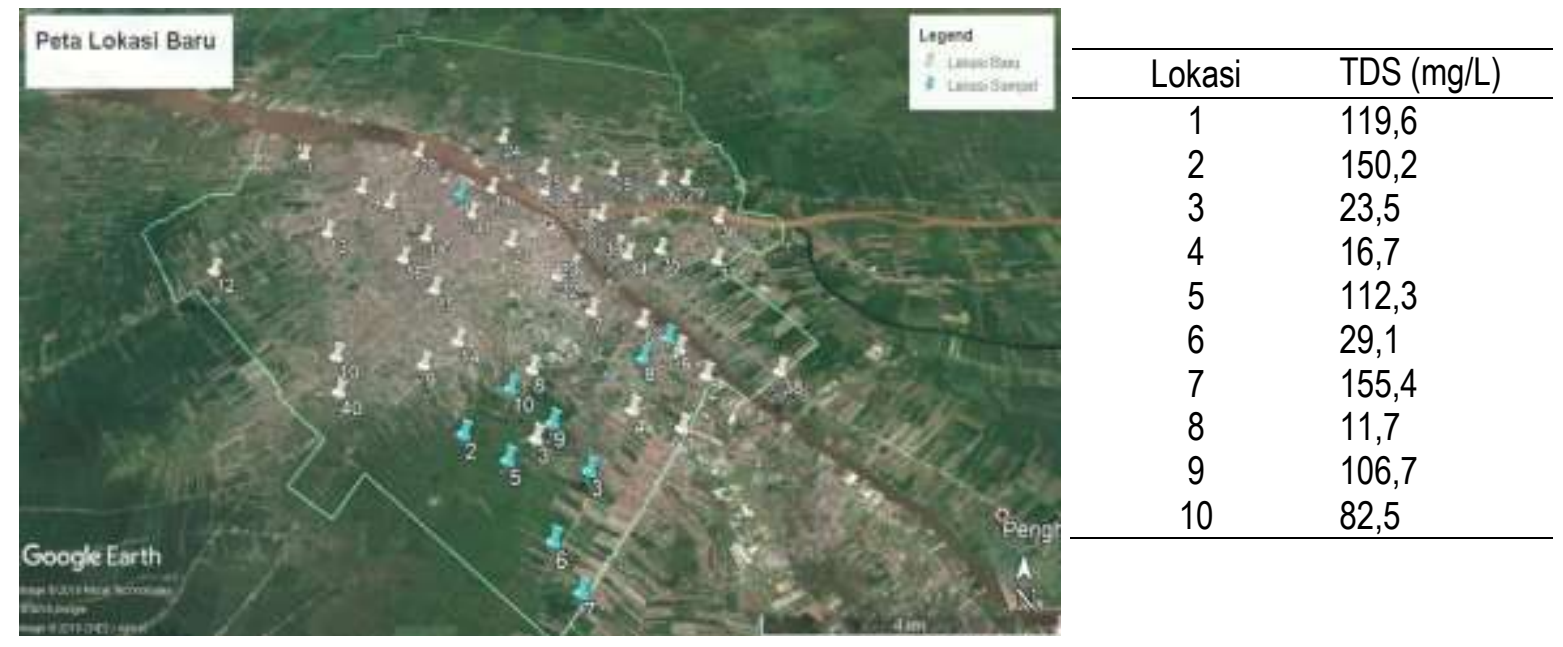

Gambar 3. Peta lokasi TDS hasil estimasi

Dari nilai estimasi TDS yang diperoleh dapat disimpulkan kandungan TDS di Kota Pontianak masih di bawah ambang batas.

\section{SIMPULAN}

Dari hasil analisis diperoleh model semivariogram teoritis untuk variabel TDS yang digunakan adalah model eksponensial, untuk variabel warna adalah model spherical, serta cross semivariogram antara TDS dan warna adalah model spherical. Estimasi TDS dilakukan pada sepuluh titik lokasi yang ditentukan. Hasil estimasi TDS terbesar sebesar 155,4 mg/L dan hasil estimasi terkecil sebesar $11,7 \mathrm{mg} / \mathrm{L}$. Dari nilai-nilai hasil estimasi tersebut, kualitas air di kawasan permukiman Kota Pontianak untuk keperluan higiene sanitasi masih tergolong baik.

\section{UCAPAN TERIMA KASIH}

Ucapan terima kasih disampaikan kepada Fakultas Matematika dan IImu Pengetahuan Alam universitas Tanjungpura atas dukungan dana bagi penelitian ini.

\section{REFERENSI}

Armstrong, M. (1998). Basic linear geostatistics. Berlin: Springer.

Cressie, N. (2015). Statistics for spatial data. Revised Edition. New York.: John Wiley\& Sons Inc.

Debataraja, N. N., Kusnandar, D., \& Nusantara , R. W. (2018). Identifikasi lokasi sebaran pencemaran air di kawasan permukiman Kota Pontianak. Jurnal Matematika, Statistika, dan Komputasi, 15(1), 37-41.

Isaaks, H,E \& Srivastava, R. (1989). Applied geostatistics. New York: Oxford University Press. 
Republik Indonesia. (2017). Peraturan Menteri Kesehatan Republik Indonesia Nomor 32 Tahun 2017 Tentang Standar Baku Mutu Kesehatan Lingkungan dan Persyaratan Kesehatan Air Untuk Keperluan Higiene Sanitasi, Kolam Renang, Solus per Aqua dan Pemandian Umum. Jakarta: Sekretariat Negara.

Wackernagel, H. (1995). Multivariate geostatistic: An introduction with applications. New York: Springer. 


\section{INDEKS JURNAL MATEMATIKA, SAINS, \& TEKNOLOGI \\ TAHUN 2019}

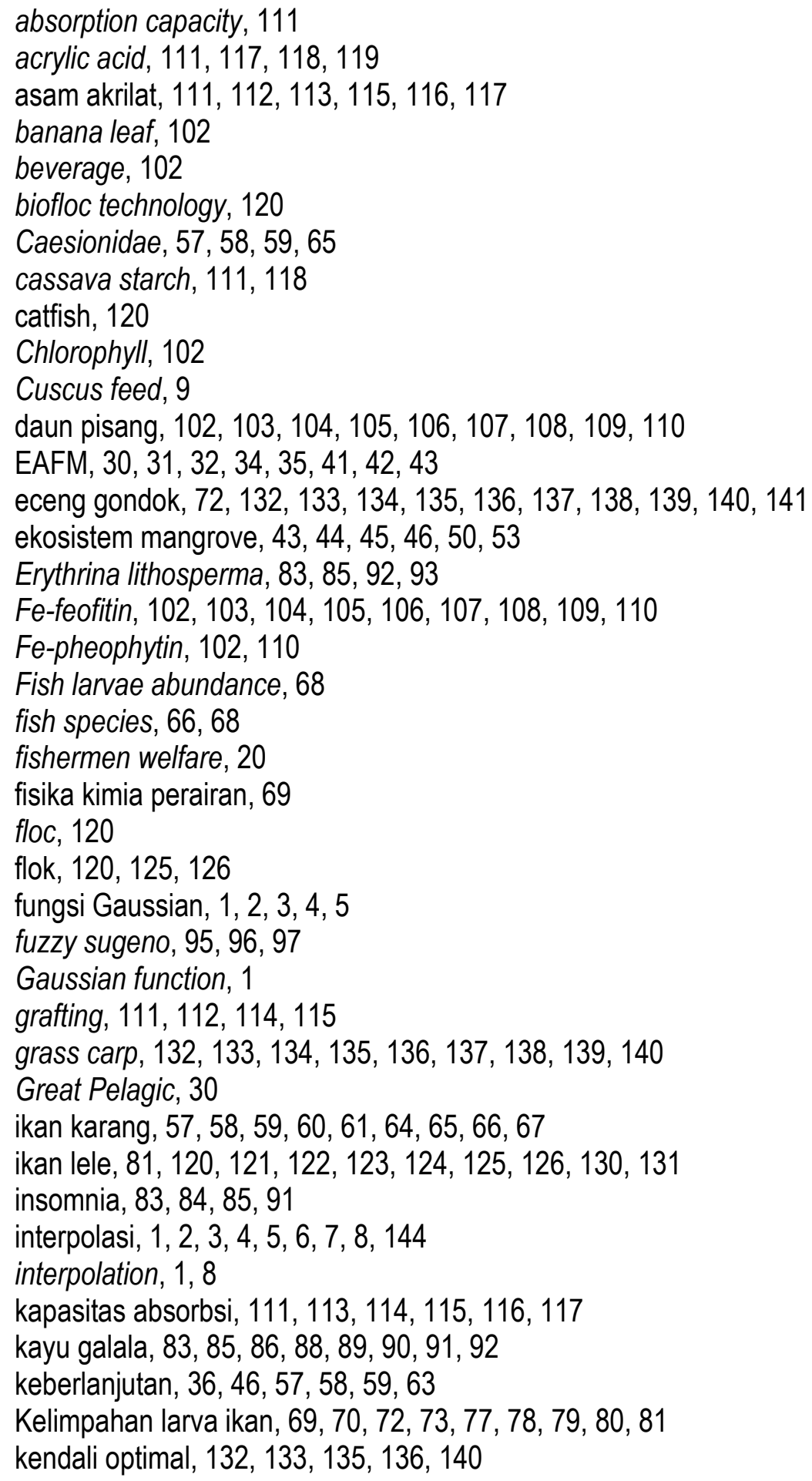


kesejahteraan nelayan, 20,21, 22, 28, 40

kesesuaian lahan, 45, 47, 48, 49, 50, 51, 52, 54

klorofil, 36, 102, 103, 104, 105, 106, 110

komposit polimer superabsorban, 111, 112, 113, 114, 115, 116, 117

kriging, 142, 144, 145

land suitability, 45

Mamuju Utara, 30, 31, 32, 35, 36, 37, 38, 39, 40, 41, 42, 43

management strategy, 20

mangrove ecosystem, 45, 54

Manusela National Park, 9

minuman, 84, 102, 103, 104, 105, 106, 107, 108, 109, 110

nilai parameter $\mathrm{c}, 1,4,5,8$

North Mamuju, 30

Pakan kuskus, 10

parameter value of $c, 1$

pati singkong, 111, 112, 113, 115, 116, 117

Pelagis Besar, 31, 32, 42

pemanenan, 132, 133, 134, 136, 137, 138, 139, 140

pengelolaan, $11,20,21,22,25,26,27,28,29,30,31,32,35,37,39,40,41,42,43,52,53,58,59$, $60,63,64,65,66,67,68,69,81$

Phalangeridae, 9, 10, 11, 13, 15, 19

physicochemical parameters of water, 68

Plants, 9

Pontryagin, 132, 133, 135

PPI, 20, 21, 22, 23, 25, 26, 27, 28, 29

reef fish, 57, 66, 67

rehabilitasi, 45, 46, 47, 48, 49, 50, 52, 53, 54, 55

rehabilitation, 45,55

rute terbaik, 95

sedatif-hipnotik, 83, 84, 85, 88, 90, 91, 92

sedative-hypnotic, 83

semivariogram, 142, 144, 145, 146, 147, 148

Sistem Informasi Geografis, 142

Spasial, 142

spesies ikan, 58, 63, 69

strategi pengelolaan, 20, 21, 22, 26, 27, 69

superabsorbent polymer composites, 111

Surabaya tourism, 95

sustainability, 19, 57, 66

Taman Nasional Manusela, 10, 11, 12, 13, 18, 19

teknologi bioflok, 120, 121, 122, 123, 126, 130

the best route, 95

Tumbuhan, 10, 13, 15, 73, 85

wisata Surabaya, 95 


\section{INDEKS PENULIS JURNAL MATEMATIKA, SAINS, \& TEKNOLOGI TAHUN 2019}

Aceng Hidayat, 45

Agnes P. Sudarmo, 68

Alsuhendra, 102, 103, 104, 110

Anang Suhardianto, 120

Anwar Kasim, 111

Aris Alfan, 132

Ariyanti Hartari, 120

Athanasia Amanda Septevani, 111

Bambang Pramudya Noorachmat, 45

Budhi H. Iskandar, 68

Cecep Kusmana, 45

Chomsa Dintasari Umi Baszary, 83

Dadan Kusnandar, 142

Efraim Samson, 83

Elin Herlinawati, 1

Ernik Yuliana, 57

Etty Riani, 30, 68

Fitroh Resmi, 132

Idha Farida, 57

Iswahyudi, 45

Lina Warlina, 20

Marwalida Rachmadiar, 142

Muizzatul Mukaromah, 95

Naomi Nessyana Debataraja, 142

Nia Istiani Wahid, 30

Novelina, 111

Nurfitri Imro'ah, 142

Nurhasanah, 57

Ridawati, 102, 103, 104, 110

Rinda Noviyanti, 20, 30

Rony Marsyal Kunda, 9

Slamet Ifandi, 132

Sri Hartanti, 20

Sri Kurniati Handayani, 9

Tuah N. M. Wulandari, 68

Wahyudi Abdul Hamid Ridwan, 83

Weni Fika, 111 


\title{
INDEKS PENYUNTING JURNAL MATEMATIKA, SAINS, \& TEKNOLOGI TAHUN 2019
}

Untuk penerbitan Volume 20 Tahun 2019, semua naskah yang diserahkan kepada Jurnal Matematika, Sains, dan Teknologi (JMST) telah ditelaah oleh para pakar/mitra bestari/rekan setara berikut:

\author{
Lina Warlina (Universitas Terbuka) \\ Ludivica Endang Setijorini (Universitas Terbuka) \\ Dwi Astuti Aprijani (Universitas Terbuka) \\ Andriansyah (Batan) \\ Atun Ismarwati (Universitas Terbuka) \\ Benny Suprapto (Institut Teknologi Bandung) \\ Diki (Universitas Terbuka) \\ Eko Yuliastuti (Universitas Terbuka) \\ Etty Riani (Institut Pertanian Bogor) \\ Harmi Sugiarti (Universitas Terbuka) \\ Hurip Pratomo (Universitas Terbuka) \\ Jan Hotman (Universitas Terbuka) \\ Jarnuzi Gunlazuardi (Universitas Indonesia) \\ Mohamad Agus Setiadi (Institut Pertanian Bogor) \\ Nurmala Pangaribuan (Universitas Terbuka) \\ Sonny Suwasono (Universitas Jember) \\ Sri Listyarini (Universitas Terbuka) \\ Sudradjat Supian (Universitas Padjadjaran) \\ Susi Sulistiana (Universitas Terbuka) \\ Winarso Drajad Widodo (Institut Pertanian Bogor)
}

Ucapan terima kasih dan penghargaan setinggi-tingginya kepada para pakar/mitra bestari/rekan setara

tersebut atas bantuannya 